\title{
ESTUDO DA SUSTENTABILIDADE E RESPONSABILIDADE SOCIAL NO SETOR DE CONCESSÃO DE RODOVIAS BRASILEIRAS
}

\section{STUDY OF SUSTAINABILITY AND SOCIAL RESPONSIBILITY IN THE BRASILIAN ROADS CONCESSION SECTOR}

\author{
Ernane Orsi de Aguiar \\ Cassia Regina Bianchini Teixeira ${ }^{\text {II }}$
}

\begin{abstract}
RESUMO
O presente artigo apresenta um estudo de caso sobre o "Projeto Escola Educar para Humanizar o Trânsito", desenvolvido pela empresa Arteris S/A. O objetivo dessa pesquisa é investigar as práticas relativas à sustentabilidade e responsabilidade social, de uma das maiores empresas do setor de concessão de rodovias brasileiras. Para tanto, foi utilizada a pesquisa qualitativa. O levantamento dos dados foi realizado por meio da pesquisa documental e da revisão bibliográfica que inclui artigos científicos, livros, revistas e sites especializados e de domínio público. Os resultados obtidos confirmaram que o "Projeto Escola Educar para Humanizar o Trânsito" colabora com a construção de um perfil de alunos mais conscientes, e ainda, que eles semeiam os conhecimentos adquiridos no projeto por toda a sociedade. No que tange a responsabilização do cidadão, foi exposta a forma como o projeto desenvolve sua proposta de ação. Mostrou-se ainda, o impacto no cotidiano não só dos alunos, como também dos professores e comunidade em geral. Concluiu-se que o projeto atinge os objetivos propostos ajudando na formação de jovens e adultos mais conscientes de suas responsabilidades no trânsito.
\end{abstract}

Palavras-chave: Educação. Trânsito. Sustentabilidade. Responsabilidade Social.

\begin{abstract}
This paper presents a case study on the "Educating School Project to Humanize the Transit", developed by the company Arteris S / A. The objective of this research is to investigate the practices related to sustainability and social responsibility of one of the largest companies in the Brazilian highway concession sector. For this, the qualitative research was used. Data collection was performed through documentary research and literature review that includes scientific articles, books, periodical and website specialized and public domain websites. The results obtained confirmed that the "Educating School Project to Humanize the Transit" collaborates with the construction of a profile of more conscious students, and also that they sow the knowledge acquired in the project throughout society. With regard to citizen accountability, it was exposed how the project develops its action proposal. It was also shown the impact on daily life not only of the students, but also of the teachers and community in

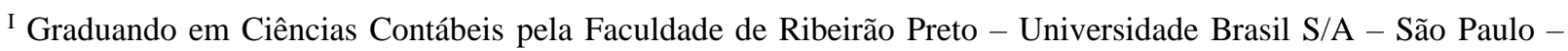
Brasil. E-mail: eoaguiar@hotmail.com.

II Profa. Me. da Faculdade de Ribeirão Preto - Universidade Brasil S/A - São Paulo - Brasil. E-mail: bianchinicr@yahoo.com.br.
\end{abstract}




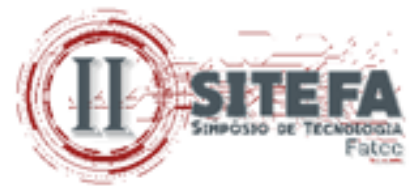

general. It was concluded that the project achieves the proposed objectives by helping to train young people and adults more aware of their responsibilities in traffic.

Keywords: Education. Traffic. Sustainability. Social Responsability.

Data de submissão do artigo: 04/07/2019.

Data de aprovação do artigo: 01/10/2019.

DOI:

\section{INTRODUÇÃO}

Temos visto que acidentes no trânsito, nas cidades ou nas rodovias, ocorrem frequentemente em vários países do mundo, e, no Brasil, a situação não é diferente. Os números são assustadores, porém podemos dizer que o trânsito pode ser uma causa de morte evitável. A maioria dos acidentes ocorre pelo chamado "fator humano", isto é, imprudência, desrespeito às leis de trânsito e, até mesmo, a desatenção do motorista (BRASIL, 2018).

$\mathrm{Na}$ tentativa de reduzir o número de ocorrências de acidentes no trânsito, existem programas preventivos que alertam a população sobre este assunto. Esses programas partem do governo federal, de concessionárias estaduais e federais, estas de domínio da iniciativa privada, adquiridas por meio do programa de concessão rodoviária (BRASIL, 2018).

O governo federal através do Ministério da Infraestrutura possui o projeto a "Semana Nacional do Trânsito", realizada em setembro, desde 1991. O propósito é envolver toda a sociedade na reflexão de suas atitudes no trânsito, estimulando todos os condutores (sejam motoristas, passageiros e pedestres) a optarem por um trânsito mais seguro (BRASIL, 2018).

Já as concessionárias estaduais e federais, hoje formadas por 51 empresas privadas que atuam em doze estados, operam 17.531 quilômetros de rodovias (ABCR, 2019), investem em programas de sustentabilidade que têm como objetivo a valorização da vida por meio da formação de cidadãos conscientes no trânsito (REVISTA VIVA, 2016, p. 17).

Diante do exposto, esse artigo tem por objetivo investigar as práticas relativas à sustentabilidade e responsabilidade social, por meio de um estudo de caso, analisando o "Projeto Escola Educar para Humanizar o Trânsito", um programa de sustentabilidade da Arteris S/A, uma empresa privada que atua no ramo de concessões rodoviárias e possuí nove concessionárias, sendo quatro concessionárias estaduais e cinco concessionárias federais. $\mathrm{O}$ projeto possui como aliados às escolas e educadores que estão dispostos a incorporar em seus programas pedagógicos o tema trânsito (ARTERIS, 2019a).

Partindo do pressuposto de que a educação contribui para a formação de cidadão, temas transversais são incluídos nas escolas, de acordo com a Lei de Diretrizes e Bases $\mathrm{n}^{\circ}$ 9.394 de 1996. Dessa forma, inclui-se, nas escolas, o projeto anteriormente mencionado, o qual versa sobre a importância da formação de pessoas mais conscientes em relação ao respeito no trânsito.

Para que tal premissa obtenha resultado satisfatório, é necessário um planejamento, expondo cada item a ser desenvolvido no projeto. Faz-se necessário, também, mostrar o impacto na vida atual dos alunos envolvidos em tal tema transversal, para que os resultados não sejam vistos apenas à longo prazo. 


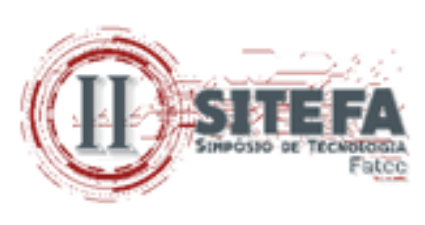

\section{CONCESSÕES DE RODOVIAS NO BRASIL}

A concessão é uma outorga onde o poder público repassa a uma empresa privada a execução de determinado serviço público que era de sua competência, tais como: construções, ampliações, melhorias e conservação total ou parcial de obras de interesse público.

De acordo com a Associação Brasileira de Concessionárias de Rodovias (ABCR, 2019), o Brasil tem atualmente 51 concessionárias, administram 17 mil quilômetros de rodovias e atuam em doze estados do País: Bahia, Espírito Santo, Goiás, Minas Gerais, Mato Grosso do Sul, Mato Grosso, Paraná, Pernambuco, Rio de Janeiro, Rio Grande do Sul, Santa Catarina e São Paulo.

Segundo Grotti (2004, p. 13):

Concessão de serviço público é o contrato administrativo pelo qual o Estado atribui a alguém o exercício de um serviço público, para que o execute em nome próprio, por sua conta e risco, remunerando-se pela própria exploração do serviço, via de regra, mediante tarifas cobradas diretamente dos usuários do serviço.

A concessão, no quesito rodoviário, é o contrato realizado entre o poder público e a empresa privada onde a empresa privada passa a assumir todas as responsabilidades de um determinado lote rodoviário adquirido através em um leilão. A empresa vencedora tem em seu contrato de concessão o período de início e fim, que ela administrará o lote rodoviário, assim como cláusulas contratuais onde prevê investimentos em ampliações ou manutenções e possíveis novas construções (PEREIRA; ESPEJO, 2012).

A Constituição Federal Brasileira de 1988, no artigo 175, confia ao poder público prestar serviço público diretamente ou se ocorrer sobre regime de concessão, deverá ser por meio de licitação, sendo necessária uma lei para regular sobre o regime das concessionárias, o caráter especial de seu contrato e de sua prorrogação, rescisão, política tarifária e obrigação de manter o serviço adequado (BRASIL, 1988; PEREIRA; ESPEJO, 2012).

O artigo 175 da Constituição Federal brasileira serviu de base para a elaboração da Lei 8.987, de 13 de fevereiro de 1995, que dispõe sobre o regime de concessão e permissão de serviços públicos. A referida lei em seu artigo $5^{\circ}$ estabeleceu que a concessão do serviço público deverá ser realizada por meio de processo licitatório, onde deverá estar justificado a conveniência da concessão, a área e o prazo, entre outros (BRASIL, 1995).

\subsection{Sustentabilidade}

Sustentabilidade é um conceito sistêmico, relacionado com a continuidade dos processos econômicos, sociais, culturais e ambientais globais, ou seja, é obter um crescimento econômico utilizando-se dos recursos naturais de forma racional preservando a biodiversidade e a qualidade de vida das pessoas (LASSU, 2019).

A relação entre meio ambiente e desenvolvimento ganhou impulso em 1962, com a obra da bióloga Rachael Louise Carson, intitulada "Silent Spring" (Primavera Silenciosa), onde ela denunciou os malefícios causados pelos agrotóxicos ao meio ambiente e aos seres vivos (ONU, 2019).

A ideia de sustentabilidade surgiu a partir da intensificação dos movimentos ambientalistas na década de 70. Estes movimentos provocaram a convocação, em 1972, pela Organização das Nações Unidas, a chamada "Conferência das Nações Unidas sobre o 


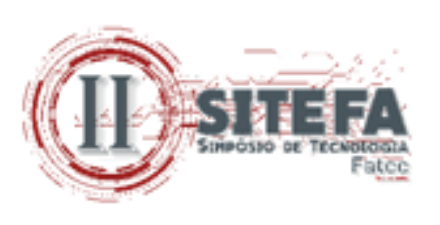

Ambiente Humano", em Estocolmo (Suécia), esta reunião foi considerada, pelos ambientalistas, um passo importante, pois foi adotado o termo "Ecodesenvolvimento" para designar o desenvolvimento que considerava conceitos multidisciplinares (econômico, ecológico e social) para evidenciar a relevante relação entre meio ambiente e desenvolvimento (BIANCHINI; MEDAETS, 2013).

No encerramento dos trabalhos da conferência citada acima, foi apresentado o chamado Manifesto Ambiental, onde foram expostos 19 princípios para guiar nossos tempos. O Manifesto Ambiental ao abordar a necessidade de "inspirar e guiar os povos do mundo para a preservação e a melhoria do ambiente humano" ele estabeleceu bases para a nova agenda ambiental (ONU BRASIL, 2019).

Em 1987, a Comissão Brundtland (comissão encabeçada pela mestra em saúde pública e presidente da Comissão Mundial sobre o Meio Ambiente e Desenvolvimento, Gro Harlem Brundtland), publicou o relatório "Nosso Futuro Comum" que traz o conceito de desenvolvimento sustentável como sendo aquele que utiliza os recursos naturais sem comprometer a capacidade das gerações futuras, em substituição ao termo "ecodesenvolvimento" (SEIFFERT, 2007; ONU BRASIL, 2019).

O conceito de sustentabilidade definido pela Organização das Nações Unidas é sustentado por três pilares: ambientais, sociais e econômicos (ONU, 1991).

Em paralelo à ideia dos três pilares da sustentabilidade definidos pela ONU, o economista polonês naturalizado francês Ignacy Sachs acrescenta dois pilares a definição de sustentabilidade "Sustentabilidade rural/urbana e a sustentabilidade cultural" (BIANCHINI; MEDAETS, 2013, p.2).

\subsection{Responsabilidade social}

Atualmente, a população tem se mostrado mais preocupada com as questões ligadas a sustentabilidade, esta atitude promove o questionamento e a exigência de uma conduta mais responsável, em relação à atuação da empresa perante a sociedade e o meio ambiente (GARAY; FONT, 2012).

A organização pode adotar a responsabilidade social por motivos distintos, tais com: altruísmo, ganhar competitividade e legitimidade. Esses fatores podem levá-la a obter um desempenho financeiro melhor (GARAY; FONT, 2012; BOULOUTA; PITELIS, 2014).

\subsection{Lei de Diretrizes e Bases (LDB)}

A Lei de Diretrizes e Bases da Educação, $\mathrm{n}^{\circ}$ 9.394, de 20 de dezembro de 1996, também conhecida como LDB, completou vinte anos em 2016. Ela é considerada por muitos um marco histórico no sistema educacional brasileiro (BRASIL, 2016).

A LDB é incumbida de regulamentar e estruturar o sistema educacional brasileiro, definir objetivos e, também, fortificar o caráter federativo da educação (BRASIL, 2016).

De acordo com a Lei de Diretrizes e Bases, vê-se o apontamento da necessidade de se trabalharem temas transversais nas escolas:

Conteúdos relativos aos direitos humanos e à prevenção de todas as formas de violência contra a criança e o adolescente serão incluídos, como temas transversais, nos currículos escolares de que trata o caput deste artigo, tendo como diretriz a Lei no 8.069, de 13 de julho de 1990 (e do Adolescente), observada a produção e distribuição de material didático adequado (BRASIL, 2017, p. 22). 


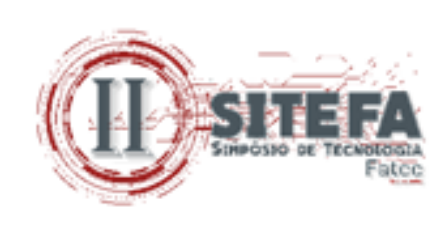

Segundo o Ministério da Educação e Cultura é evidente que essa Lei contribuiu positivamente com a educação no país. (BRASIL, 2016).

A seguir será apresentado o "Projeto Escola Educar para Humanizar o Trânsito" que se enquadra nos temas transversais mencionados na Lei de Diretrizes e Bases da educação brasileira. (BRASIL, 1996)

\subsection{Projeto escola educar para humanizar o trânsito}

O Projeto Escola, desenvolvido pela empresa Arteris S/A, possui o objetivo de formar cidadãos responsáveis e conscientes de que suas atitudes podem impactar no trânsito. Ele atende aos alunos de escolas públicas, creches, educação infantil, fundamental I e II, ensino médio, APAE e a EJA - Educação de jovens e adultos, inserindo no contexto escolar a compreensão do respeito à vida e a humanização do trânsito. Esses conceitos quando assimilados pelos alunos podem extrapolar a sala de aula e transformar alunos em agentes multiplicadores (ARTERIS, 2019a).

O "Projeto Escola Educar para Humanizar o Trânsito" foi concebido observando os quatro pilares da educação, do século XXI, disseminado pela UNESCO, a saber: "Aprender e conhecer, aprender a fazer, aprender a viver juntos, aprender a ser" (ARTERIS, 2019a, p.2).

A Arteris S/A entende que "tão importante quanto cuidar de estradas é tornar o trânsito mais humano", foi esse pensamento que inspirou a criação do Projeto Escola, um programa de educação com quase 20 anos, teve início em 2001, na Concessionária de Rodovias do Interior Paulista S/A e replicados às demais concessionárias da companhia a partir de 2013. A ação beneficia as escolas localizadas nos munícipios que são abrangidos pelas concessionárias da Arteris (ARTERIS, 2019a, p.1; REVISTA VIVA, 2016, p. 21).

$\mathrm{O}$ intuito do projeto é de gerar uma mudança de comportamento no ser humano relacionado ao tema trânsito. O projeto tem como foco a humanização do trânsito, a cidadania, a ética e o convívio social. Esses valores são trabalhados com alunos e professores por meio de ações pedagógicas e de conscientização. São implementados palestras, dinâmicas, concursos de desenhos e frases, entre outras inciativas (ARTERIS, 2019a; REVISTA VIVA, 2016, p. 23).

\section{METODOLOGIA}

A pesquisa realizada caracteriza-se como exploratória-descritiva. Exploratória no sentido de aprofundar os conhecimentos sobre o tema e o prisma descritivo aplica-se à descrição do "Projeto Escola Educar para Humanizar o Trânsito" (VERGARA, 2016).

O presente trabalho apresenta um estudo de caso, do projeto em tela, e para atingir os objetivos dessa pesquisa utilizou-se a abordagem qualitativa. Em relação aos dados coletados, foram empregadas as fontes bibliográficas, tais como: informações de sites institucionais e especializados de acesso público, livros, revistas especializadas, artigos científicos e fontes documentais (VERGARA, 2016).

Para analisar seu impacto, parte-se dos objetivos propostos pelo "Projeto Escola Educar para Humanizar o Trânsito" e os resultados obtidos na revisão bibliográfica e documental, fornecendo o embasamento para as considerações finais (LAKATOS; MARCONI, 1991). 


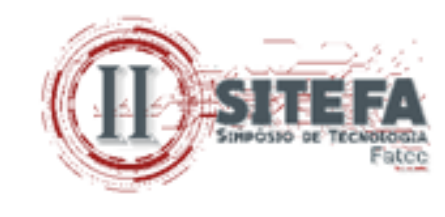

\section{RESULTADOS E DISCUSSÕES}

Alunos conscientizados, em relação ao trânsito, contribuem para que este seja menos violento. Em parceria com escolas, esse objetivo é buscado e atendido por meio do "Projeto Escola Educar para Humanizar o Trânsito" por meio de visitas externas e internas.

As visitas externas ocorrem nas escolas que recebem a equipe do Projeto Escola, uma parceria que envolve a Polícia Militar Rodoviária, equipes de resgate e a própria concessionária (representada pelo funcionário da área de sustentabilidade do Projeto Escola), o objetivo é mostrar aos alunos o conceito de valores e respeito à vida levando em consideração ações de mobilidade e atitudes corretas no trânsito. Um exemplo de visita externa realizada foi na Escola Municipal de Educação Infantil Deputado Leônidas Pacheco Ferreira, na cidade de Bocaina, estado de São Paulo. O evento contou com a participação de 380 alunos e 21 professores. Os participantes conheceram melhor o trabalho da concessionária, das equipes da Polícia Militar Rodoviária e equipes de Resgate (ARTERIS, 2019b, p. 6; REVISTA VIVA, 2016, p. 28).

As visitas internas ocorrem na própria concessionária com um número reduzido de alunos e professores, o objetivo é de intensificar as orientações e dicas de segurança no trânsito, valorização da vida, informar quais são as principais causas de acidentes na rodovia, chamar a atenção para a imprudência, conscientizar a respeito dos direitos e deveres. Como resultado da visita interna encontra-se o trabalho desenvolvido com a Escola Municipal João Paulo II, na cidade de Campo do Tenente, estado do Paraná, onde 23 alunos e 02 professores participaram de demonstrações de primeiros socorros pela equipe de Resgate, palestras sobre segurança, boas práticas no trânsito e com a preservação do meio ambiente. Os participantes conheceram também as demais áreas da empresa (ARTERIS, 2019c, p.6; REVISTA VIVA, 2016, p. 28).

Ao ingressar no Projeto Escola, a instituição recebe um kit com materiais pedagógicos contendo: álbuns seriados, jogos educativos, código de trânsito brasileiro, vídeo educativo (enaltecendo valores trabalhados no contexto do projeto), fantoches, dedoches, tudo isso no intuito de trabalhar a transversalização do tema trânsito com os alunos. O material foi desenvolvido, cuidadosamente, levando em conta o ciclo de ensino, ele se baseia na realidade hoje vivida no trânsito (REVISTA VIVA, 2016, p. 24).

Os coordenadores pedagógicos e professores participam anualmente de capacitações onde é explicado como aplicar as atividades propostas pelo projeto aos seus alunos e essa capacitação tem como fundamento estabelecer debates, troca de experiências e interação entre todos os participantes (REVISTA VIVA, 2016, p. 25).

Por fim as atividades realizadas pelas escolas junto com os alunos são postadas em um site próprio do projeto onde se estabelece uma boa troca de experiências entre os educadores participantes, criando assim uma rede de conhecimento (REVISTA VIVA, 2016, p. 28-29).

As escolas participantes criam por meio da transversalização do tema trânsito, atividades que possam estimular os alunos despertando o conceito de educação no trânsito. Como resultado obtido, podemos verificar as atividades a seguir.

\subsection{Escola Municipal Jardim Muniz}

Os alunos da Escola Municipal de Jardim Muniz, na cidade de Cajati, estado de São Paulo, promoveram uma passeata em prol a vida, com elaboração de cartazes, o intuito foi de alertar a população sobre os cuidados no trânsito e na oportunidade, os alunos puderam 


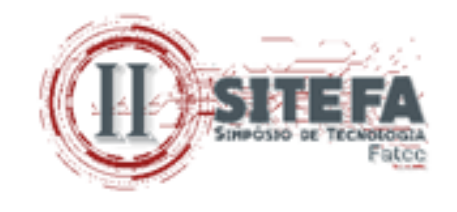

aprender a utilizar a faixa de pedestre, usar a calçada e estar sempre atentos, pois os pedestres necessitam colaborar também com o trânsito, conforme ilustra a Fotografia 1.

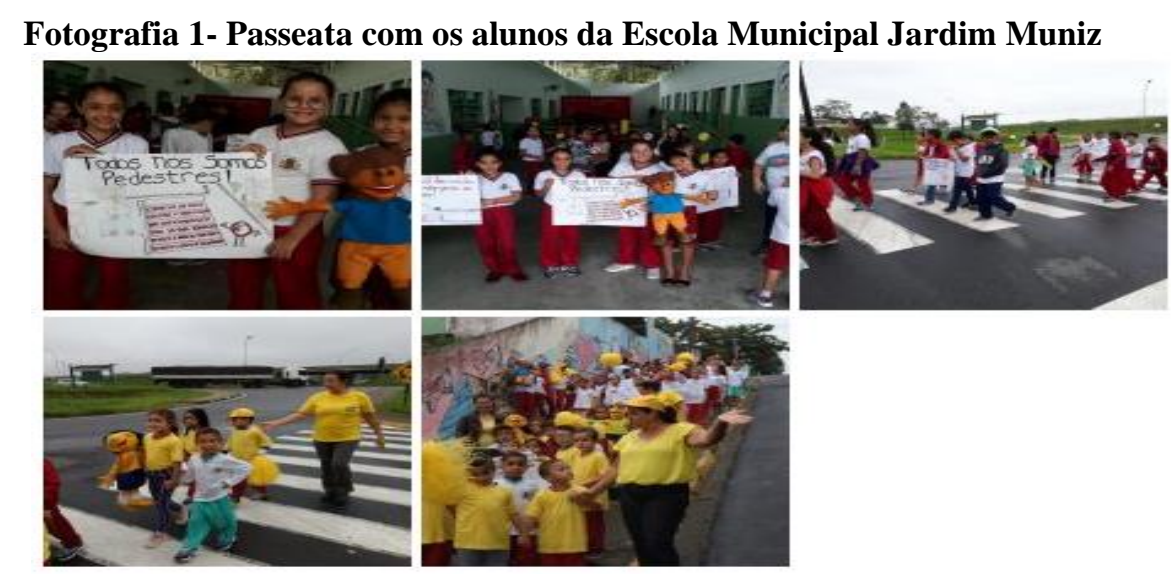

Fonte: Arteris (2019d)

\subsection{Estudando normas de trânsito}

Alunos de $4^{\circ}$ e $5^{\circ}$ ano (escola não divulgada no site do projeto), estudaram em sala de aula as Normas de Trânsito, os professores mostraram aos alunos participantes a importância de estudar o tema e fizeram uma abordagem dos pontos positivos e negativos.

Como fixação de conhecimento, foi realizado um "Quiz" com torta na cara onde os alunos tinham que responder perguntas relacionadas ao que fora aprendido com o estudo das Normas de Trânsito, conforme registro da Fotografia 2.

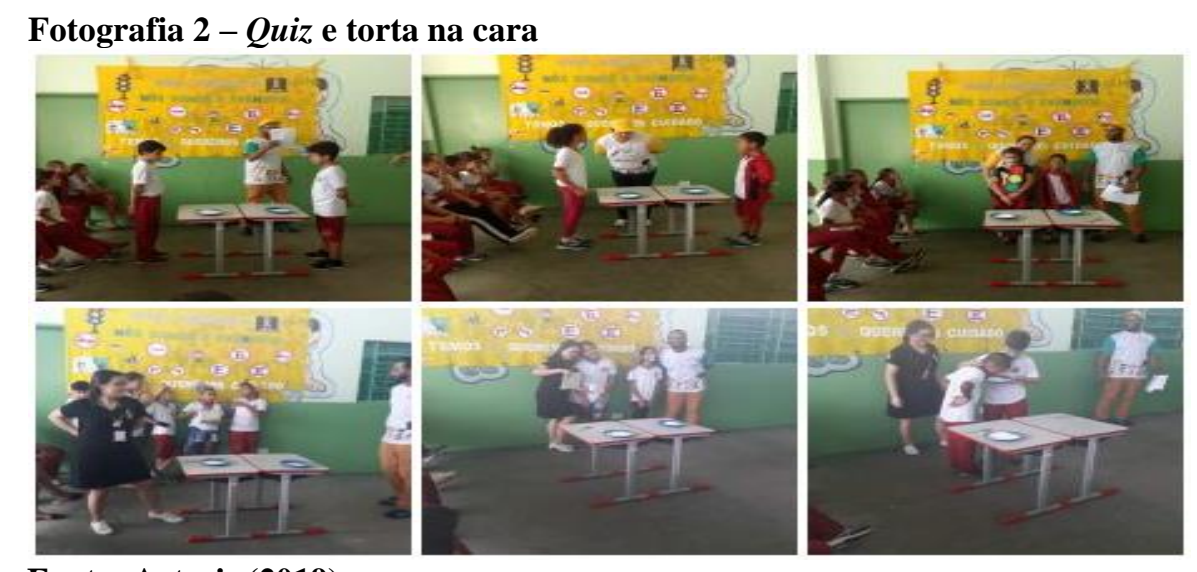

Fonte: Arteris (2019)

\subsection{EMTI Professora Iolanda Jorge}

Os alunos do $5^{\circ}$ ano, da Escola Professora Iolanda Jorge, da cidade de São Simão, estado de São Paulo, promoveram uma apresentação de abertura oficial das atividades do Projeto Escola. Para o ano de 2019 o tema escolhido pela escola é: "Todo mundo tem direito a vida, todo mundo tem direitos iguais!" e tem como objetivo de trabalhar a atividade, a 


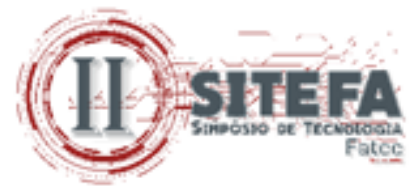

diferença entre as pessoas e no trânsito, entender e respeitar as pessoas com algum tipo de dificuldade, tanto física, como intelectual, e/ou neurológica, conforme Fotografia 3.

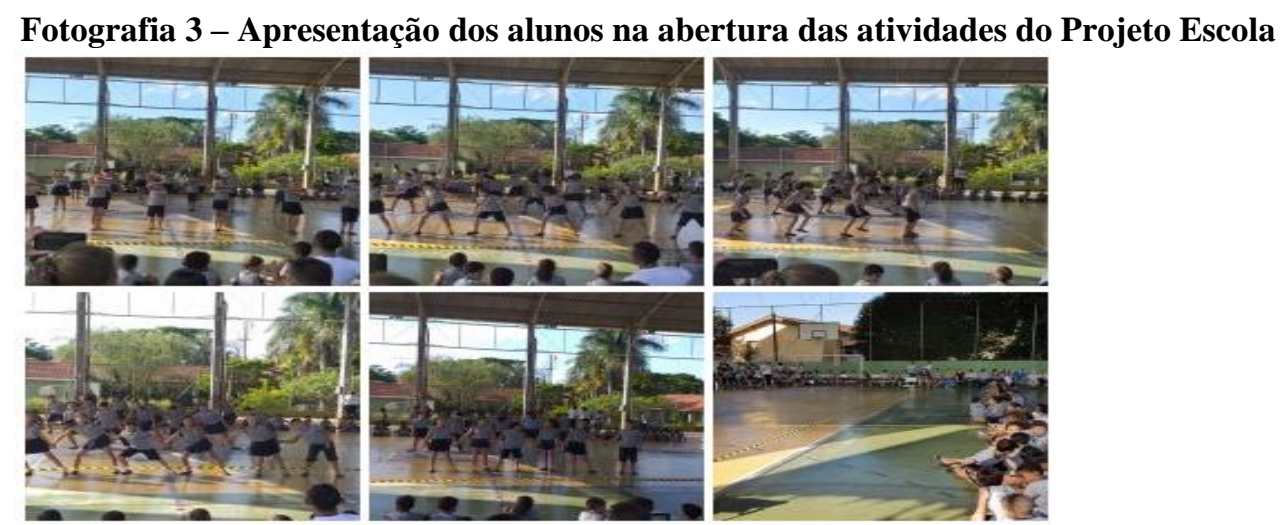

Fonte: Arteris (2019e)

\subsection{Reunião Pedagógica}

Duas concessionárias estaduais, a Autovias e Via Paulista, controladas pela Arteris S/A promoveram em maio de 2019 a primeira reunião pedagógica de seus programas de Sustentabilidade.

O objetivo do encontro, que contou com a participação de 54 educadores de 19 cidades das macrorregiões de Ribeirão Preto, Franca e Jaú, do estado de São Paulo, foi integrar os representantes das unidades de ensino público e apresentar os diversos materiais pedagógicos que podem ser utilizados em sala de aula para tratar de trânsito e meio ambiente. $\mathrm{N}$ ocasião foi apresentado aos participantes a nova plataforma de Sustentabilidade da empresa na qual comtemplará o conteúdo de trabalho das escolas participantes, conforme Fotografia 4.

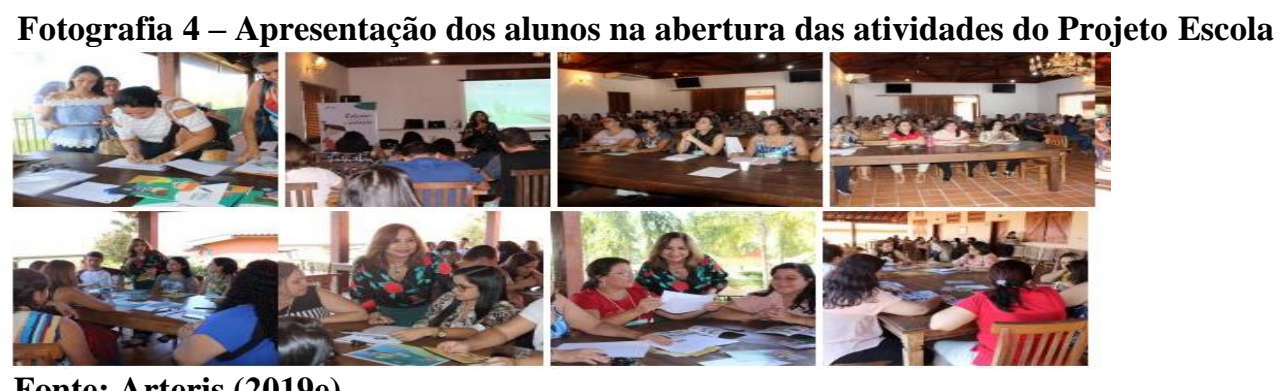

Fonte: Arteris (2019e)

Em análise das fontes bibliográficas obtidas no site e em revista da empresa, foi constatado que o sucesso das propostas idealizadas pelo Projeto Escola só terá efeito positivo se a direção e os professores estiverem motivados ao abordarem o tema educação no trânsito com os alunos, pois acredita-se que comportamentos mais seguros no trânsito é mais efetivo se a cobrança partir dos filhos aos pais e os pais certamente irão pensar duas vezes antes de cometer alguma imprudência (REVISTA VIVA, 2016, p. 25). 


\section{CONSIDERAÇÕES FINAIS}

Este artigo teve como objetivo investigar as práticas relativas à sustentabilidade e responsabilidade social, de uma das maiores empresas do setor de concessão de rodovias brasileiras.

Uma das práticas da empresa, na área de Sustentabilidade, é o "Projeto Escola Educar para Humanizar o Trânsito". Ele é implementado em escolas que estão na área de abrangência das concessionárias controladas pela Arteris S/A. A empresa que atua no ramo de concessões de rodovias e tem como objetivo trabalhar a transversalização proposta na "Lei de Diretrizes e Bases (LDB)" idealizada pelo Senado Federal (BRASIL, 1996).

Reafirma-se a positividade do Projeto Escola Educar para Humanizar o Trânsito pelos resultados educativos alcançados por meio das atividades sugeridas pelo referido projeto e também, pela capacidade de multiplicação do tema assimilado pelos professores, tais temas são repassados aos alunos por meio de atividades diversas, desenvolvendo assim conceitos sobre educação no trânsito e como esses alunos podem ser futuros motoristas conscientes.

Partindo da ideia da formação de futuros motoristas conscientes, existe uma enorme possibilidade de que esses alunos possam levar para as pessoas nas quais eles se relacionam aquilo que estão aprendendo ou o que aprenderam sobre educação no trânsito.

Por fim, é necessário abordar a importância dos encontros pedagógicos promovidos pela equipe do Projeto Escola aos educadores, pois os encontros fornecem momentos de debates, interações e principalmente, trocas de experiências entre os educadores participantes.

\section{REFERÊNCIAS}

ABCR - Associação Brasileira de Concessonárias de Rodovias. Quem somos. 2019. Disponível em: https://abcr.org.br/institucional/institucional/quem-somos . Acesso em: 25 ago. 2019.

ARTERIS S/A. Sobre Arteris. 2019. Disponível em: http://www.arteris.com.br/institucional/ sobre-a-arteris-s-a/ . Acesso em: 29 mar. 2019.

.Projeto Escola Arteris. O Programa - Projeto Escola. 2019a. Disponível em: http://www.projetoescolaarteris.com.br/arquivos/page.aspx?id=25. Acesso em: 04 maio 2019.

.Sustentabilidade. Ações. Visita Externa, 2019b. Disponível em:

https://sustentabilidade.arteris.com.br/2019/06/13/visita-externa-viapaulista-atividadeeducativa-na-emef-deputado-leonidas-em-bocaina/. Acesso em: 23 jun. 2019.

.Sustentabilidade. Ações. Visita Interna, 2019c. Disponível em: https://sustentabili dade.arteris.com.br/2019/06/11/1-visita-interna-2019-planalto-sul/. Acesso em: 23 jun. 2019

.Sustentabilidade. Ações. Passeata pela vida. 2019d. Disponível em:

https://sustentabilidade.arteris.com.br/

escolaemacao/passeata-pela-vida/. Acesso em: 23 de jun. de 2019.

.Sustentabilidade. Abertura oficial do projeto - apresentacao do $5^{\circ}$ ano. 2019e.

Disponível em: https://sustentabilidade.arteris.com.br/ 


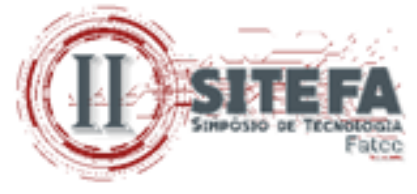

escolaemacao/abertura-oficial-do-projeto-apresentacao-do-5o-ano/.Acesso em: 23 de jun. de 2019.

BIANCHINI, V.; MEDAETS, J. P.P. Da revolução verde à agroecologia: Plano Brasil Agroecológico (MDA) 2013.p. 1-28.

BOULOUTA, I.; PITELIS, C. N. Who needs CSR? The impact of corporate social responsibility on national competitiveness. Journal of business ethics, v. 119, n. 3, p. 349-364, 2014.

BRASIL.Ministério da Infraestrutura. Estudo aponta que mais de 50\% dos acidentes de trânsito são causados por falhas humanas. Sistema Nacional do Trânsito, 2018. Disponível em: http://infraestrutura.gov.br/component/content/article/17-ultimas-noticias/7999-estudoaponta-que-mais-de-50-dos-acidentes-de-tr\%C3\% A2nsito-s\%C3\%A3o-causados-por-falhashumanas.html. Acesso em: 27 maio 2019

.Senado Federal. LDB - Leis de Diretrizes e Bases. Brasília. 2017. Disponível em: http://www2.senado.leg.br/bdsf/bitstream/handle/id/529732/lei_de_diretrizes_e_bases_1 ed.pdf. Acesso em: 09 jun. 2019.

. Ministério da Educação e Cultura (MEC). Lei de Diretrizes e Bases da Educação completa 20 anos e continua atua. 2016. Disponível em: http://portal.mec.gov.br/buscageral/211-noticias/218175739/43311-lei-de-diretrizes-e-bases-da-educacao-completa-20anos-e-continua-atual. Acesso em: 27 jun. 2019.

Presidência da República. Lei 9.394 de 1996. Estabelece as diretrizes e bases da educação nacional. 1996. Disponível em: http://www.planalto.gov.br/ccivil_03/LEIS/L9394.htm. Acesso em: 02 de jun. 2019.

Presidência da República. Lei 8.987 de 1995. Dispõe sobre o regime de concessão e permissão da prestação de serviços públicos previsto no art. 175 da Constituição Federal, e dá outras providências.1995. Disponível em: http://www.planalto.gov.br/ccivil_03/LEIS/L8987 cons.htm. Acesso em: 02 jun. 2019.

Presidência da República. Constituição Federal de 1988. 1988. Disponível em: http://www.planalto.gov.br/ccivil_03/Constituicao/Constituicao.htm\#art175. Acesso em: 02 jun. 2019.

GARAY, L.; FONT, X. Doing good to do well? Corporate social responsibility reasons, practices and impacts in small and medium accommodation enterprises. International Journal of Hospitality Management, v. 31, n. 2, p. 329-337, 2012 GROTTI, D. A. M. A experiência brasileira nas concessões de serviços públicos. 2004. p.13.

LAKATOS, E. M.; MARCONI, M.A. Fundamentos de metodologia científica. 3.ed.São Paulo: Atlas, 1991. 270 p. 
LASSU, L. D. S. Mas afinal, o que é sustentabilidade?, 2019. Disponível em: http://www .lassu.usp.br/sustentabilidade/conceituacao/. Acesso em: 08 jun. 2019.

ONU BRASIL. Meio ambiente. Organização das Nações Unidas, 2019. Disponível em: https://nacoesunidas.org/acao/meio-ambiente/. Acesso em: 08 jun. 2019.

Comissão mundial sobre meio ambiente e desenvolvimento. Nosso futuro comum. 2. ed. Rio de Janeiro: FGV, 1991.

PEREIRA, F. D. A.; ESPEJO, M. M. D. S. B. Planejamento e Controle Orçamentário em Empresas Concessionárias de Rodovias: uma pesquisa empírica. UFSC. Florianópolis. 2012. (ISSN 2175-8069).

REVISTA VIVA. 15 anos do Projeto Escola Arteris. Revista Viva, São Paulo, v. 08, p. 66, nov. 2016.

SEIFFERT, M. E. B. Gestão Ambiental. 3. ed. São Paulo: Atlas, 2007.

VERGARA, S. C. Projetos e Relatórios de Pesquisa em Administração. 16. ed. São Paulo: Atlas, 2016. 